\title{
3. The view from the Greater Mekong Subregion, Association of Southeast Asian Nations Economic Community, and the Central Asia Regional Economic Cooperation Region
}

\section{CONTEXTUAL FRAME AND TRENDS OF CLUSTER DEVELOPMENT IN THE GREATER MEKONG SUBREGION AND THE ASSOCIATION OF SOUTHEAST ASIAN NATIONS ECONOMIC COMMUNITY}

This chapter will trace and identify the development of innovation clusters in the Greater Mekong Subregion (GMS), as well as in parts of the Central Asia Regional Economic Cooperation (CAREC) areas. Here zones and clusters that provide skill-based products and services and that have actual or potential strong linkages to global and regional value chains are of prime interest. It is crucial to determine, for instance, if there is a history of development of an interlinked set of innovation clusters, as determined by increasing value-added trade flows among the set ('innovation-clusterecology'). As has been shown in the case of the BSR, a 'bottom-up' as well as 'top-down' driven institutional regional integration and skill-based innovation structure has been established successfully, under a somewhat integrated set of strategic knowledge tools, with which policy makers were able to build an innovation-cluster-ecology. Smaller states with less innovation capacity profited from integration with innovation leaders. In the Association of Southeast Asian Nations (ASEAN), and therefore for most of the GMS, regional innovation capacity-building is influenced by the relative importance of intraregional versus extraregional economic (especially trade in value-added) asymmetry (Krapohl and Fink, 2013).

GMS countries' trade structure is characterized by extraregional interdependence in global value chains. This is apparent from GMS regional 
value-added trade flow data (see Figures 1.8 and 1.9), and values are given by key sectors in Figure 3.1. The numbers are corroborated by field visits and interviews. The main export zones and research and innovation clusters in Thailand, Viet Nam and Yunnan Province, the People's Republic of China PRC depend on intermediate inputs from the industrialized East Asian economies and from the eastern coastal areas of the PRC. This is also where the bulk of value added is exported (plus the European Union and North America). Thus, the GMS can still be characterized as a region dependent on central, urban nodes located at the coast for the integration in GVCs. This situation in the GMS indicates clear opportunities for consensual governance, policies and tools that build up a cooperative innovation cluster investment plan in the region.

Nonetheless, intra-industry trade between PRC, Thailand and Viet Nam has been sharply increasing and is reflected in a deepening structure of value chain specialization between the PRC and each of its trading partners. Intra-industry trade in electronic, electrical equipment has expanded especially rapidly in this case. In the case of Yunnan Province, withincountry inter-industry trade is heavy between the highly industrialized east coast regions and Yunnan.

The foremost investment needed in the GMS is the establishment of a regional coordinator (secretariat) of cluster-network-based cooperation. Such a coordination arrangement can be housed in a critical innovation hub of the GMS. The coordinator will act as facilitator, creating and maintaining connection with the public sector, the business community, and the non-profit education and research sectors (a triple helix), and the international networks in the related products and fields. Under the coordinator structure, priority innovation steering groups could be chaired by representatives from different countries, according to national priorities. The kinds of instruments and tools that can be employed in the GMS context are platforms and tools for dialogue and networking between the triple helix cluster stakeholders, including construction of actual and virtual meeting spaces, creation of knowledge-enhancing partnerships and twinning arrangements (such as under the proposed Asian Regional Economic Integration Observatory, AREIO), and the building of comparable innovation cluster statistics and data anchored in geography, that is, geographic information systems (GIS)-compatible.

\subsection{History and Current State of Innovation Cluster Development}

\section{Thailand}

The National Electronics and Computer Technology Center, a statutory government organization under the National Science and Technology 


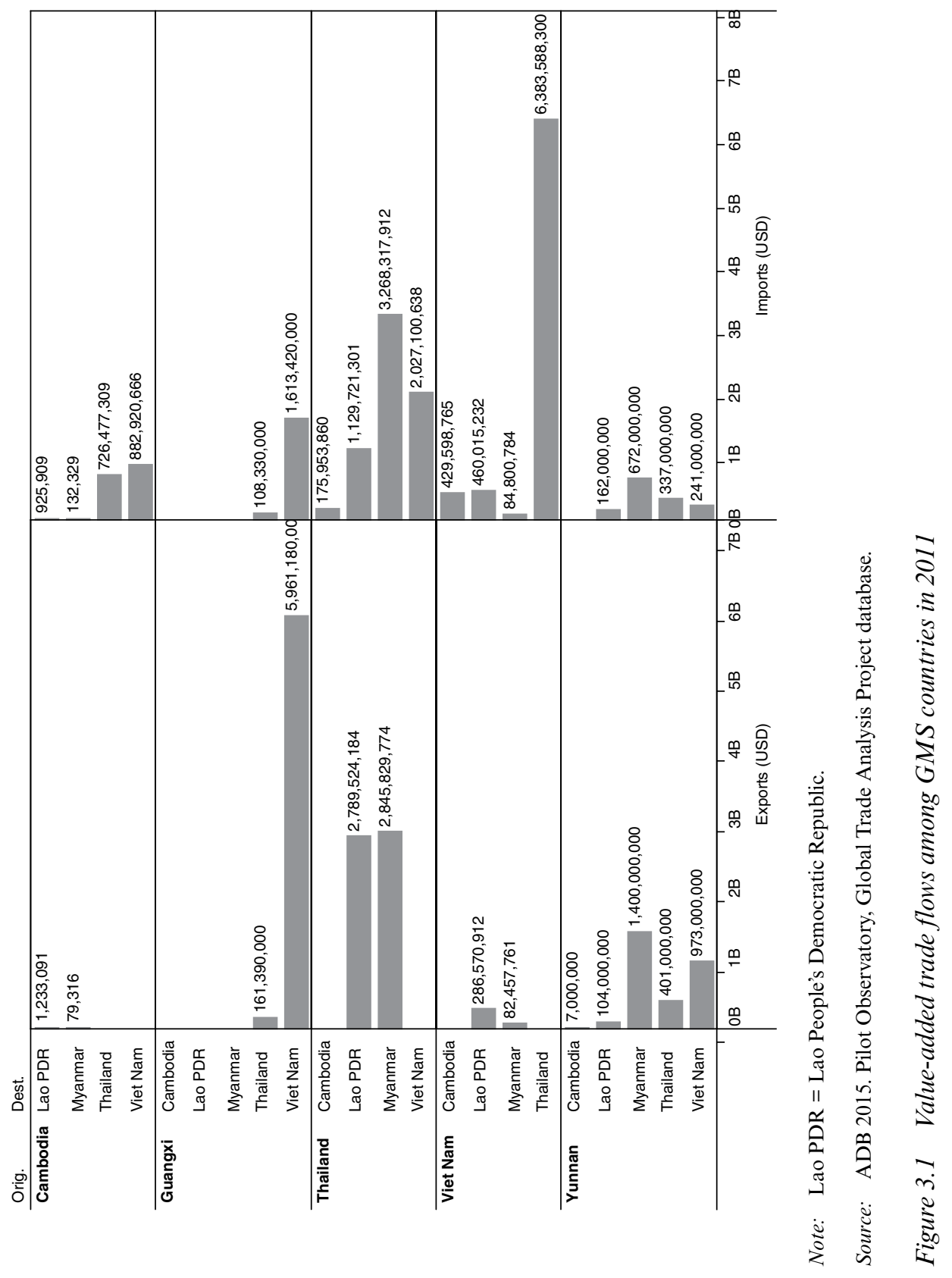


Development Agency (NSTDA), Ministry of Science and Technology, was founded in 1986 to encourage technology transfers and collaborations between private and public sectors in the field of electronics and computer technologies (National Electronics and Computer Technology Center, 2014). The mission of NSTDA is to promote research and development activities, technology transfer, human resources development, and infrastructure development for the field of science and technology (NSTDA, 2014). The early stage of science and technology development in Thailand was also promoted through the 6th national economic and social development plan (implemented during 1987-91). The plan laid out several development guidelines to increase the efficiency of national development by improving the quality of the working population, utilizing science and technology, and improving the efficiency of government and state enterprises. One of the economic programs included in the plan specifically addressed the development of science and technology (Government of Thailand, 1987). In 2002, the Thailand Science Park, a fully integrated $\mathrm{R} \& \mathrm{D}$ hub for science and technology, was set up to continue the initiatives to strengthen Thailand's capabilities in research and innovation. With its advanced facilities and business space, the Thailand Science Park offers a full range of value-added services to support technology businesses. It currently houses the NSTDA headquarters as well as the four national research centers: the National Center for Genetic Engineering and Biotechnology, the National Metal and Material Technology Center, the National Electronics and Computer Technology Center, and the National Nanotechnology Center.

Most of the industrial zones in Thailand are privately owned, developed and managed. As presented in Figure 3.2, the majority of industrial zones are in the center and east of Bangkok. The Board of Investment in Thailand has divided the country into three zones based on economic factors. Based on the earnings and primary facilities as the key criteria of each province, seven cities, including Bangkok, Nakhon Pathom, Nonthaburi, Pathoum Thani, Samut Prakan and Samut Sakhon are in Zone 1. Zone 2 consists of 12 provinces, mostly located in the center of Thailand. The remaining 59 provinces are in Zone 3, due to low incomes and lessdeveloped infrastructure. Each zone has different incentives, including both tax and non-tax incentives, which can be varied from zone to zone. The highest privileges are reserved for areas furthest from Bangkok.

There are three major industrial parks located in nearby Bangkok areas, as depicted in Figure 3.2.

- Nava Nakorn is located in Pathoum Thani (Zone 1): The zone is attractive to companies that are suppliers of companies already 


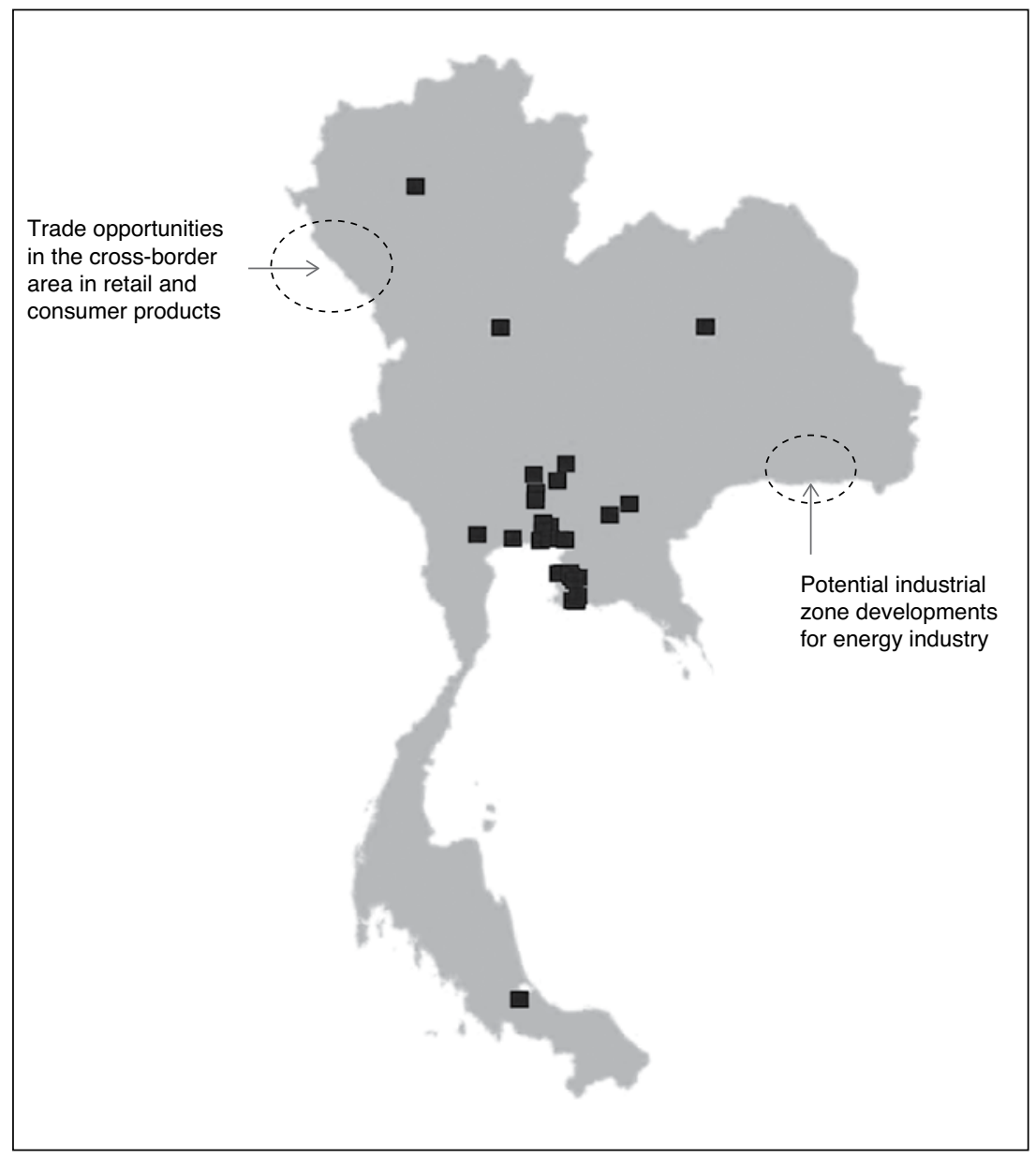

Source: Danuvasin et al. (2015) mapped to Fu (2015) pilot GIS Observatory.

Figure 3.2 Overall key zones map in Thailand

located in the zone. Currently, the zone is home to over 200 foreign and domestic companies.

- Rojana Ayutthya Industrial Park is a Thai-Japanese joint venture, located a 30-minute drive farther out from Bangkok. It is Board of Investment Zone 2, with very large facilities to host a number of large manufacturers, such as the Honda Auto assembly. 
- Amata Nakorn is located in Chonburi, Thailand (Zone 3). It is in the heart of the eastern seaboard, which allows for easy access to Laem Chabang Port and is home to major foreign and domestic manufacturing plants.

\section{Viet Nam}

In Viet Nam, until the 1980s, government policies had focused on constructing heavy industries. New guidelines for industrialization were introduced at the 7th Party Congress in 1991 to include new and advanced science and technology as a basis for growth and enhanced economic achievement (Van, 2012). In the same year, the first and most successful export processing zone in Viet Nam, Tan Thuan Export Processing Zone, was established in Ho Chi Minh City to promote economic development through high value-added industries, trading and services. Out of 146 companies in the Tan Thuan Export Processing Zone, more than 118 companies have increased their investment capital and/or expanded their production scale (Tan Thuan Corporation, 2012). In 2013 the Ministry of Planning and Investment took the lead in establishing a 'Strategy for Development of Industrial Clusters toward 2020 and the Vision of 2030 in Viet Nam'. This strategy is, for instance, prioritizing industries such as electronic, electrical equipment. The objective is to increase the domestic share of economic value added, and to catalyze industrial restructuring in favor of high-tech production.

With the exception of the PRC (of which Yunnan and Guanxi Provinces are part of the GMS), Viet Nam has been the most active GMS country in the use of zones for economic development. Viet Nam now has industrial zones, economic zones, export processing zones, and more recently high-tech zones. Approximately 250 industrial zones have been established with a total capital input of $\$ 70$ billion from more than 8500 investment projects. The zones are located in the three major economic areas in northern, central and southern areas. However, Viet Nam's experience with zones has been decidedly more mixed in terms of economic benefits than has been case in the PRC.

The major industrial zones in the southern key economic area (see Table 3.1) are located in the following cities: surrounding urban centers of Binh Duong, Donh Nai and Ho Chi Minh City. These are cities with the highest infrastructure index (top three cities), especially in the score of industrial zones, which measure the availability and quality of local industrial zones. Additionally, Binh Duong, Donh Nai and Ho Chi Minh City have a high infrastructure score in the coverage of roads, the reliability of telecommunications and energy delivery, and information and communications technology. Figure 3.3 shows the locations of all industrial and exporting zones in Viet Nam. 
Table 3.1 Viet Nam geographic distribution of key industrial zones

\begin{tabular}{lcc}
\hline Geographical area & $\begin{array}{c}\text { Number of industrial } \\
\text { zones }\end{array}$ & $\begin{array}{c}\text { GVIO (1994 constant } \\
\text { VND, \%) }\end{array}$ \\
\hline Total & 267 & 808745 billion \\
Key economic areas (KEAs) & 199 & 74.2 \\
of which & & \\
Northern KEA & 52 & 24.0 \\
Central KEA & 23 & 5.4 \\
Southern KEA & 124 & 44.8 \\
Outside KEAs & 68 & 25.8 \\
\hline
\end{tabular}

Note: $\quad$ GVIO $=$ Gross Value Industrial Output $; \mathrm{VND}=$ Viet Nam Dong.

Source: Nestor (2013, p. 125).

\section{The People's Republic of China (PRC)}

The government of the People's Republic of China began to propose and implement national programs for science and technology in the 1980s. In 1982, the Key Technologies R\&D Program was launched as the largest science and technology program in the country, with most funds invested, most personnel employed, and greatest impact on the national economy. The program focuses on national economic construction, engaging more than 1000 scientific research institutions in the field of agriculture, electronic information, energy resources, transportation, environmental protection, medical and health care, and other fields. In 1986, the government launched the National High-Tech R\&D Program (also known as 863 Program), which covers 20 areas such as biotech, laser, automation and space flight. This program helps determine the future direction of research based on observation of the latest development of international scientific research, and facilitates the use of results in industries. Another science and technology program launched in 1986 is the Spark Program. The program's main objective is to expand the development of science and technology to rural areas. As a result, more than 100000 science and technology projects are being carried out in 85 percent of rural areas throughout the country. The PRC's most important program for high-tech industries was launched in 1988, known as the Torch Program. The program promotes the development of high-tech products with economic value for both domestic and foreign markets, establishes high-tech industrial development zones around the country, and explores managerial and operational mechanisms to support high-tech industrial development. Lastly, in 1998, the 973 Program was launched to encourage scientists to conduct research on issues with 


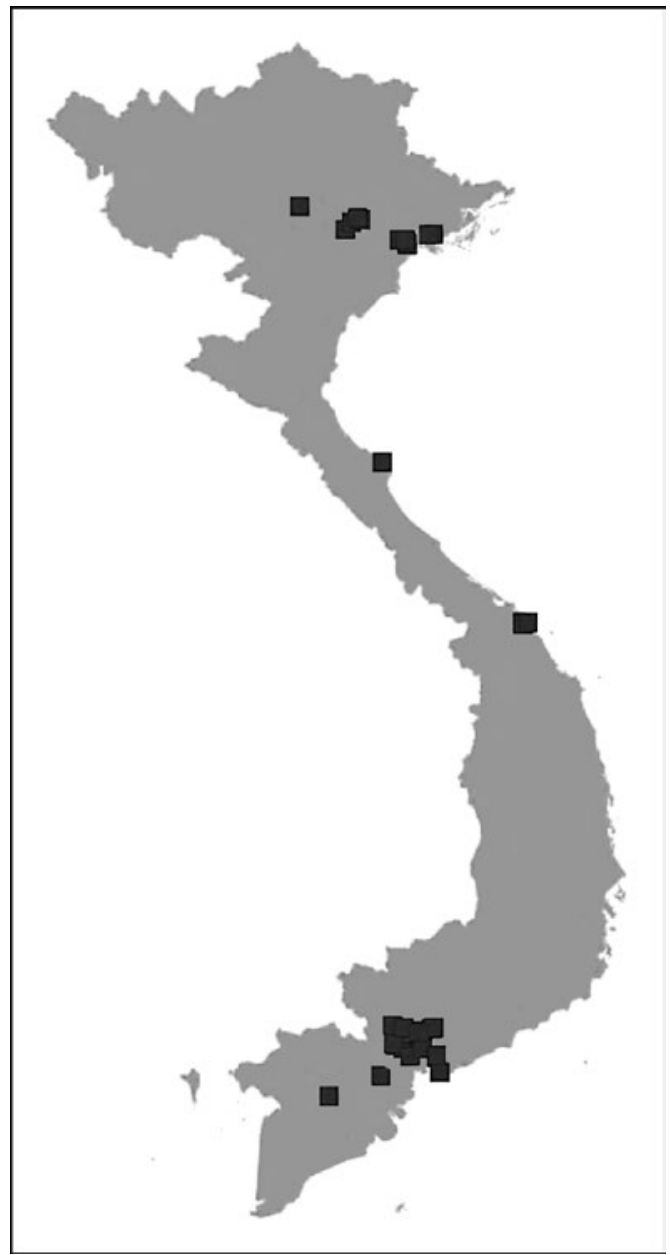

Source: Danuvasin et al. (2015) mapped to Fu (2015) pilot GIS Observatory.

Figure 3.3 Viet Nam's key industrial map

significant impact on economic and social development in the twenty-first century (China Internet Information Center, 2004).

The PRC meanwhile has a wide range of zones, including special economic zones, economic and technological development zones, high-tech industrial development zones, free trade zones, export processing zones, bonded logistics zones, and cross-border economic zones. 


\section{Yunnan Province (PRC)}

The Yunnan provincial government has launched a 'regionalization' project centered on Kunming. Around Kunming, the government plans to build and cultivate agglomerated networks of competitive clusters (Su, 2014). This, then, is intended to become a bridgehead for interaction and integration with emerging clusters in GMS. There are two major high-tech industrial zones in Kunming: Kunming Economic and Technological Development Zone and Kunming High-Tech Industrial Development Zone (KHIDZ), which are the only two national high-tech development zones in Yunnan Province. The GDP of the Kunming Economic and Technological Development Zone and KHIDZ is estimated at RMB17.85 billion ( $\$ 2.88$ billion) and RMB15.46 billion ( $\$ 2.5$ billion) respectively, which accounted for about 10 percent of the city's total in 2012 (Chinaknowledge.com).

Kunming Economic and Technological Development Zone is located in the eastern part of the center of Kunming and is only $1.8 \mathrm{~km}$ from Kunming International Airport. The utilized FDI of the zone was estimated at \$254.05 million, which is about 16 percent of Kunming's total FDI. Kunming Economic and Technological Development Zone is one of the major high-tech zones in Kunming, Yunnan. Established in 1992, it is one of the industrial parks with the highest degree of manufacturing gathering and is the only zone which integrates national-level development and export processing, facilitating scientific and technological trading in Yunnan Province. The zone has attracted investments from over 22 countries, including Germany, Thailand and the United States. The value of import and export was estimated at \$2.14 billion in 2012 and increased significantly to $\$ 5.96$ billion in 2013 (178.5 percent increase). The key manufacturing groups are in tobacco processing, mechanical manufacturing, optoelectronics and information technology industries, biopharmaceutical, and food and beverage.

Kunming High-Tech Industrial Development Zone (KHIDZ) is located in the northwestern part of the city. The new zone of KHIDZ is located in the southern Kunming's Majinpu Village. KHIDZ's value-added industrial output was estimated at RMB15.46 billion. Originally, KHIDZ was set up in 1992 by the (People's Republic of) China State Council and is the only national high-tech development zone in Yunnan Province. The KHIDZ consists of five function zones, including New Industrial Zone, High-Tech Business Zone, Bio-Innovation Zone, Entertainment Zone, and Bio-Protection Zone (see Figure 3.4). In particular, in this industrial zone, innovative clusters are developed in the following special industrial parks: (1) bio-pharmaceutical; (2) electric equipment manufacture; (3) new material; (4) university science and technology park; (5) new energy, water science, and technology and environment protection parks (http://www. 


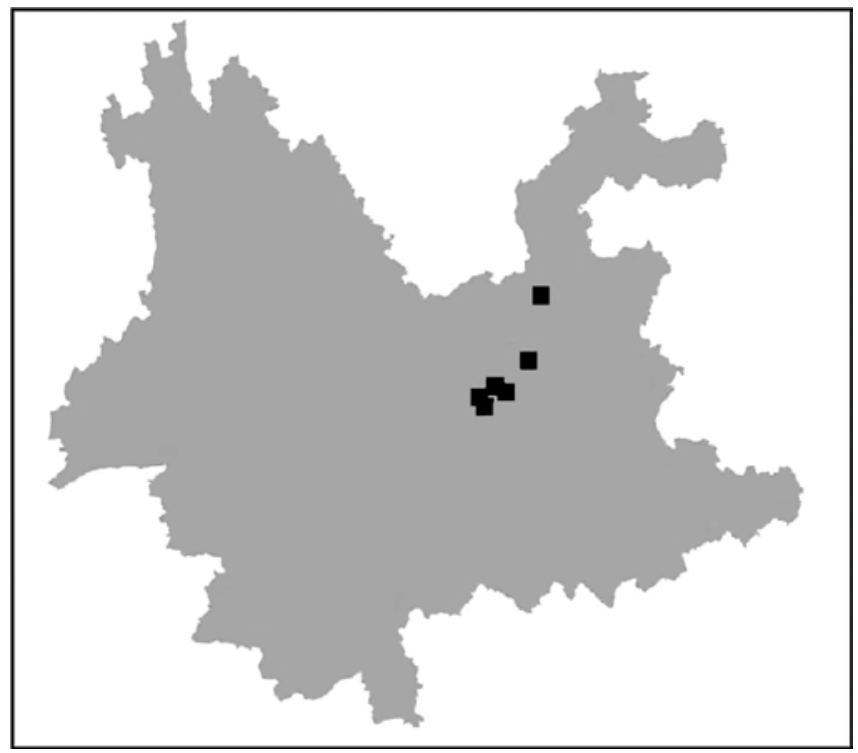

Source: Danuvasin et al. (2015) mapped to Fu (2015) pilot GIS Observatory.

Figure 3.4 Geographic maps of key industrial zones in Kunming, Yunnan

kmhnz.gov.cn/html/ehopv.html). See Figure 3.4 for the location of the key zones near Kunming, Yunnan.

\subsection{Description of Products}

In this chapter we have focused on zones and clusters that provide (potential) innovation products and services (electrical equipment focus), and that have (potential) linkage to major GVCs. These electronic electrical equipment products can be categorized in subgroups as follows (according to the Board of Investment):

1. Manufacture of electronic products including consumer electronics, office electronics, industrial electronics, telecommunication equipment, and agricultural electronics.

2. Manufacture of electronic parts and components used for electronic apparatus including semiconductors, memory storage equipment (hard disk drive), transmission cables, parts for telecommunication equipment and medical electronics, and printed circuit boards. 
3. Manufacture of automobiles including automobile engine, vehicle parts, fuel cells, industrial machinery or equipment.

Additionally, we also focus on any innovative products located in the hightech zone in each country, such as manufacture of scientific equipment, medical equipment, printers, ATM machines, or mineral and ceramic power products used in mobile phones such as liquid crystal displays (LCDs), light-emitting diodes (LEDs) and antennas.

\subsection{Success Factors}

Judging by global good practice as outlined in earlier sections, key success factors of high-tech zones and innovation clusters are geographic location, labor market conditions in skilled versus unskilled labor, access to market conditions, government policies and the related business environment, localization of knowledge flows through collaboration among think tanks, private and public sector institutions and facilities (the triple helix), and the state of regional integration. A key source looking at these drivers causing successful cluster emergence is Brenner and Muehlig (2013).

In the GMS, market access on the import and input side is well developed, less so on the export side. As already discussed, the GMS region is externally connected with global value chains; however, intraregional linkages are weak, hence, the central, urban characterization of the region. The labor force in the zones interviewed is mostly medium-skilled and wages are competitive in this segment. Government innovation and competition policies are nascent. Interviewed companies reported high variability of government policies. Triple helix linkages of zones and clusters are only at an initial stage. Businesses interviewed are focused on the local market and sometimes on national market opportunities, and many are linked locally and nationally to low to medium-tech GVCs. There is little perception and awareness of a regional GMS market. (See Table 3.2 on success factors, based on questionnaire answers.)

\subsection{Challenges}

One challenge facing GMS countries is the low level of $R \& D$ resources and activities. All GMS countries spend less than 0.5 percent of GDP on R\&D, with a concomitant effect on TFP growth (Figure 3.5; Anand et al., 2014). Thailand aims to increase R\&D spending to 1 percent of GDP, according to the National Science and Technology Development Agency (NSTDA). However, fieldwork revealed that most R\&D activities supported by the NSTDA improve the efficiency of production 
Table 3.2 On success factors, based on questions ( 8 respondents)

\begin{tabular}{|c|c|c|c|c|c|c|}
\hline \multirow[t]{3}{*}{$\mathrm{Q} \#$} & \multirow{3}{*}{$\begin{array}{l}\text { Factors } \\
\text { Geographic location }\end{array}$} & \multicolumn{5}{|c|}{ Responses of firms interviewed (GMS) } \\
\hline & & \multicolumn{5}{|c|}{ Percent international sales } \\
\hline & & $1-25$ & $26-50$ & over 50 & & \\
\hline \multirow[t]{2}{*}{5.1.} & Market access & 3 & 0 & 4 & & \\
\hline & Primary mode of shipment & Road & Rail & Air & Ship & Other \\
\hline \multirow[t]{2}{*}{7.1.} & Of inputs & 3 & 1 & 2 & 6 & 0 \\
\hline & 1) Labor market & \multicolumn{5}{|c|}{ Percent by type of workers } \\
\hline 3.1 .1 . & Low skill & 29.38 & & & & \\
\hline 3.1 .2 . & Medium skill & 56.38 & & & & \\
\hline 3.1 .3 . & High skill & 35.38 & & & & \\
\hline 3.2 .1 . & Avg wage low skill & 2 to 5 & & ratio 1 & igh/low & \\
\hline 3.2 .2 . & Avg wage medium skill & 2.5 & & ratio hig & /mediun & \\
\hline \multirow[t]{3}{*}{3.2 .3 . } & Avg wage high skill & \multicolumn{5}{|c|}{$\$ 300$ to $\$ 2000$ monthly } \\
\hline & \multirow{2}{*}{$\begin{array}{l}\text { 2) Access-to-market } \\
\text { conditions }\end{array}$} & \multicolumn{5}{|c|}{ Percent of sales } \\
\hline & & $0-25$ & $26-50$ & over 50 & & \\
\hline 5.2. & Direct exports & 3 & 1 & 3 & & \\
\hline 5.3. & Indirect exports & 4 & 1 & 1 & & \\
\hline $6.1 \mathrm{a})$. & Home imports & 1 & 3 & 3 & & \\
\hline \multirow[t]{2}{*}{$6.1 \mathrm{~b})$. } & Foreign imports & 3 & 1 & 3 & & \\
\hline & $\begin{array}{l}\text { Government policy/business } \\
\text { environment }\end{array}$ & $\begin{array}{l}\text { Very } \\
\text { good }\end{array}$ & Good & Avg & Poor & $\begin{array}{l}\text { Very } \\
\text { poor }\end{array}$ \\
\hline 1.2. & Public service quality & 4 & 1 & 4 & 1 & 0 \\
\hline 1.3. & Variability of service & 1 & 5 & 4 & 0 & 0 \\
\hline 10.5 . & $\mathrm{R} \& \mathrm{D}$ incentives (Yes/No) & \multicolumn{5}{|c|}{4 (Yes) 3 (No) } \\
\hline \multirow[t]{2}{*}{10.6} & $\begin{array}{l}\text { Environmental incentives } \\
\text { (Yes/No) }\end{array}$ & \multicolumn{5}{|c|}{2 (Yes) 5 (No) } \\
\hline & Localized knowledge flows & \multicolumn{5}{|c|}{ No } \\
\hline 3.3. & Formal training & \multicolumn{5}{|l|}{8} \\
\hline 3.4 . & TVET/universities & \multicolumn{5}{|l|}{5} \\
\hline 3.5 . & Think tanks/labs etc. & \multicolumn{5}{|c|}{3} \\
\hline \multirow[t]{2}{*}{4.3.} & $\mathrm{R} \& \mathrm{D}$ expenditure (\$) & \multirow{2}{*}{\multicolumn{5}{|c|}{ Variable answers }} \\
\hline & State of RCI & & & & & \\
\hline \multirow[t]{4}{*}{7.2.} & Primary mode of shipment & Road & Rail & Air & Ship & Other \\
\hline & Of products & 4 & 1 & 1 & 3 & 2 \\
\hline & \multirow[t]{2}{*}{ Logistics difficulty } & High cost & \multicolumn{2}{|c|}{$\begin{array}{l}\text { Delivery date } \\
\text { uncertain }\end{array}$} & \multicolumn{2}{|c|}{$\begin{array}{l}\text { Multimodal } \\
\text { connect }\end{array}$} \\
\hline & & 4 & 3 & & & \\
\hline 6.2 . & Value-added (\$) & \multicolumn{5}{|c|}{ No answers } \\
\hline \multirow[t]{2}{*}{8.1 . } & Cross-border programs & Yes & No & & Other & \\
\hline & & 2 & 6 & (e-b & Isiness p & rtal) \\
\hline
\end{tabular}

Notes: $\quad$ Avg $=$ Average $;$ GMS = Greater Mekong Subregion; $\mathrm{Q}=$ question; $\mathrm{R} \& \mathrm{D}=$ research and development; TVET = technical and vocational education and training.

Source: Author. 


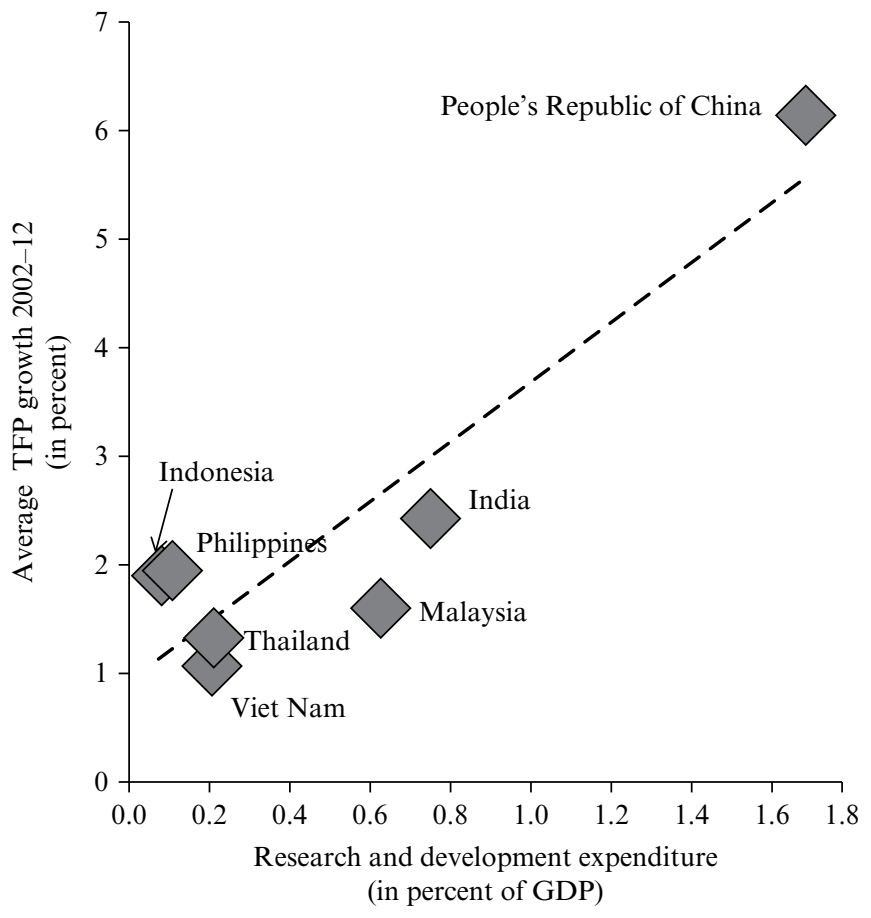

Source: Anand et al. (2014, Figure 7).

\section{Figure 3.5 Research and development expenditure and total factor productivity}

processes, rather than product innovation. In Viet Nam, it was revealed that companies in high-tech zones often have their own R\&D centers; however, there is little linkage between these centers, universities and public sector institutions and facilities. In Kunming, several interviewees confirmed that there are collaborations between local companies and universities (for example, Yunnan University, Yunnan Normal University, Johns Hopkins University); most R\&D activities are privately funded and focus on products and processes for the domestic market. Due to an insignificant amount of FDI in Yunnan, there is no strong $R \& D$ linkage between local and foreign companies, and the rest of the world (see Table 3.2).

A key strategy of Thailand, Viet Nam and Yunnan Province has been increasing attraction of FDI through high-quality infrastructure inside zones (see Table 3.3). However, this attraction does not apply to the area 
outside zones and especially in the hinterlands. Therefore, backward linkages from zones and clusters are weak or altogether missing. From interviews, it is clear that most companies in the zones are willing to do business within the zone rather than outside.

Third, skilled labor in GMS countries is undersupplied. Executives of companies in the Tan Thuan Export Processing Zone in Viet Nam admitted that their companies need to provide their own training programs to the employees to improve their professional skill sets. One interviewee also stated that high-tech companies investing in Viet Nam, such as Samsung and Intel, provide their own training for the employees. Such companies sometimes work with local universities on curriculum development.

Vietnamese locals generally take it for granted that there are no highquality universities in the country. In Yunnan, corporate executives also said that job training provided by companies is necessary to equip their employees with job-specific skills. While there are several globally renowned universities in the PRC, most of them are located in Beijing or Shanghai. In Yunnan, even the top universities in the province such as Yunnan University and Yunnan Normal University are still ranked below the top 100 universities in Asia (Times Higher Education, 2014).

One interviewee from a hard disk drive company in Thailand expressed concerns that the quality of education in Thailand lags behind that of its neighbors, and that the Thai labor force, even after graduating from college, do not have sufficient skills required for jobs in high-tech and innovative industries. This interviewee also mentioned that most high-tech

Table 3.3 On challenging factors, based on questions (13 respondents)

\begin{tabular}{|c|c|c|c|c|c|c|}
\hline \multirow[t]{3}{*}{ Q\# } & \multirow{3}{*}{$\begin{array}{l}\text { Challenging factors } \\
\text { Quality (level) of } \\
\text { insfrastructure }\end{array}$} & \multicolumn{5}{|c|}{ Responses of firms interviewed (GMS) } \\
\hline & & Very good & Good & Avg & Poor & Very poor \\
\hline & & 3 & 4 & 2 & 1 & \\
\hline 2.1.1. & Water & & 9 & 1 & 0 & \\
\hline 2.1.2. & Waste & & 8 & 4 & 1 & \\
\hline 2.1.3. & Telecom ICT & & 5 & 4 & 1 & \\
\hline \multirow[t]{2}{*}{ 2.1.4. } & Electricity & & 7 & 3 & 0 & \\
\hline & $\begin{array}{l}\text { Labor shortage } \\
\text { (skilled) issue }\end{array}$ & High cost & $\begin{array}{l}\text { Low } \\
\text { skill }\end{array}$ & \multicolumn{2}{|c|}{ High turnover } & Other \\
\hline 3.6. & Issue mentioned (no.): & 4 & 1 & \multicolumn{2}{|c|}{2} & 1 \\
\hline
\end{tabular}

Note: $\quad$ ICT $=$ information and communication technology; GMS = Greater Mekong Subregion.

Source: Author. 
companies, when looking for a FDI destination, take each country's university ranking into account. Since Thai universities are not among the top universities in Asia, Thailand is not a very attractive location for investments of high-tech and innovative industries. Out of all the universities in Thailand, only two are ranked in the top 100 Asian universities. One is ranked 50th; the other is ranked 82nd (Times Higher Education, 2014).

Fourth, language and culture differences even within a region like the GMS are still key barriers for foreign business expansion. Regional trust creation takes time, and needs to be facilitated through regional integration narratives (for example, the silk road, the old Hanse trading network in the historic BSR).

Finally, regional collaboration among R\&D institutions (the triple helix) does not (yet) exist in the GMS. There is currently no institutional initiative that has earned the trust to initiate such collaboration.

\section{Global linkages (global value chains)}

From the fieldwork undertaken, we found that there is a high linkage between foreign firms and local firms in Thailand and Viet Nam along global value chains. Most international firms in Thailand have local suppliers in Thailand. Many investors in Thailand, especially the electronics and automobile companies located in industrial and exporting zones, export the majority of the products abroad. For Viet Nam, fieldwork established that there is a strong linkage among only the firms located in the same zone. One interviewee in the Tan Thuan Export Processing Zone mentioned that 95 percent of products made in the industrial zone are exported into global value chains. In the Kunming zones, most firms located in the zones are local companies, and these companies produce their products largely for the domestic markets.

\section{OPPORTUNITIES FOR INNOVATION CLUSTER DEVELOPMENT AND SKILL-BASED CLUSTER DEVELOPMENT INITIATIVES}

\subsection{Cluster Maps in Asian Regional Economic Integration Observatory and their Relation to Regional Interconnections}

Inspecting the mapping of zones and clusters in GMS, they appear clearly disconnected. The GMS inland networks necessary for an emerging cluster ecology are absent. As the field investigations confirm as well, imports are supplied by sea, and then processed in global value chains. Yunnan 
Province is somewhat of an exception, as production is more domestic. This situation in the GMS indicates clear opportunities for consensual governance, policies and tools that build up a cooperative innovation cluster investment plan in the GMS region. An evidence-based strategy can provide strong regional priorities aligned with productivity growth impacts and regionally inclusive distribution of associated costs and benefits. A governance structure for the investment plan can deliver measurable goals to track impact.

\subsection{Skill Development Initiatives}

As skilled workers are scarce in the emerging market economies, such as in the GMS, the regionally enhanced transmission of ideas and adapted technologies would make this scarce labor resource more productive, and also would enhance productivity in cutting edge innovation locations by allowing 'farming-out' of 'imitative innovation'. However, field work has not indicated the existence of substantive regional initiatives that would strengthen flows of skilled labor within the region and among emerging innovation clusters.

\subsection{How the Components are (to be) Linked}

We have found evidence of cluster development in the GMS; however, there is no indication of collaboration among the components in the clusters. Unlike the BSR cluster ecology, GMS clusters tend to stand alone. The clusters in Cambodia, the Lao People's Democratic Republic (Lao PDR), Myanmar and Viet Nam tend to be labor intensive, while countries such as PRC (Yunnan) and Thailand can successfully create innovative clusters. As a result, there is a potential for the collaboration and integration among clusters in the GMS area. For example, suppliers of the low-end products that require labor-intensive production in the countries such as Cambodia, Lao PDR and Myanmar can provide input material for innovative clusters in the countries such as PRC and Thailand.

\subsection{What Tools are Needed? Available? Missing?}

Currently, there is some collaboration between companies, universities and public institutes on the development of science and technology in Thailand. However, these collaborations seem to occur on a small scale, not providing a very noticeably positive impact on the country's innovative cluster development. In Yunnan, although some companies have linkages with universities with respect to $R \& D$ activities, these linkages 
are primarily for individual companies' own benefits, and little spillover effects have taken place. Collaborations on R\&D activities between the private and public sectors in Yunnan are not widely observed. The situation of private-public collaborations in Viet Nam is similar to that of Yunnan, with an even lower level of R\&D activities taking place. For the other GMS countries, public-private R\&D activities are very rare, and the development of the innovation cluster has not been observed.

Cluster observatory and information systems do not exist in the GMS. The governance and monitoring of clusters are not known by most industrial zone managers, company executives and government officials. Regional cluster integration among the GMS countries, while currently not existing, is perceived by the countries as being helpful in enhancing the GMS economic status. However, GMS countries are not likely to be able to get regional cluster integration started on their own, as no country is proactive enough to raise the idea. A catalytic, trusted agent in the form of an international organization, like ADB, would be needed.

\subsection{Silk Road Plans: How Locations Play a Role in the Success of the Cluster(s)}

Above we have looked at the software and hardware components that, for instance, in the GMS could lead to a regional ecology of clusters and economic corridors. What can merge software and hardware factors into a successful agglomerating dynamic is a history of sociocultural and economic ties. The silk roads of Asia, old trading routes leading south to north from coastal areas into central Asian hinterlands, and leading east to west across the Eurasian continent, can provide such narrative for future development of an ecology of clusters and economic corridors, as has been the case in the BSR. Silk roads functioned because they were trading on principles of comparative advantage, based on differing resource endowments and technology (know-how) within and across regions. Hard and soft infrastructure, together with mediating institutional (formal and informal) structures, is driving success. The GMS (and to a lesser extent the CAREC region) have put into place some of the prerequisites for development of regional clusters and economic corridors, such as improved connectivity infrastructure, industrial structures, links into GVCs, national policy improvements, and deepened financial markets, as detailed in regional ADB-sponsored strategic frameworks (ADB, 2011).

As we have experienced in field interactions in GMS and CAREC economies, the missing parts are policy instruments and knowledge tools, which can drive a region into a successful ecology of clusters linked with economic corridors via agglomeration economies, increases in value-added 
shares in and along regional and global value chains, structural transformations into high skill industries and services. These drivers, taken together, will exploit increasing heterogeneity in production and trade across borders. Key national policy instruments such as labor market policies (migration, skill development), technology and innovation policies, cluster and corridor policies, and competition arrangements need strengthening, and at the same time they require regional coordination so that regional growth and welfare can be augmented. The BSR 'bottom-up' development of a set of decision tools for cluster development and innovation collaboration, which catalyze business connection (embeddedness), create bridges among stakeholders (physical and figurative, connectivity), and strengthen economic flows (proximity) in value-added along historic trading routes or modern silk roads can and should inspire commensurate action in Asian regions. The knowledge toolbox for this has yet to be built. This includes foremost an Asian Regional Economic Integration Observatory (AREIO). 